\title{
Online Polls and Registration-Based Sampling: A New Method for Pre-election Polling ${ }^{1}$
}

\author{
Michael Barber \\ Princeton University \\ Christopher B. Mann \\ Louisiana State University \\ J. Quin Monson \\ Kelly D. Patterson \\ Brigham Young University \\ [Accepted for Publication in Political Analysis]
}

\footnotetext{
${ }^{1}$ We thank Anand Sohkey and his colleagues at University of Colorado-Boulder for their assistance in conducting the 2010 primary surveys in Colorado and Matthew Frei of the Center for the Study of Elections and Democracy (CSED) at Brigham Young University (BYU) for his assistance in administering the surveys. We thank Lonna Atkeson, Larry Bartels, John Love, Mark A. Schulman, the anonymous reviewers, and participants in a faculty research seminar at BYU for helpful comments. Previous versions of this paper were presented at the annual meetings of the American Association of Public Opinion Research in 2010 and 2011. This research would not have been possible without the generous support of CSED at BYU, the University of Colorado-Boulder, and the University of Miami. All errors are the responsibility of the authors.
} 


\title{
Online Polls and Registration Based Sampling:
}

\section{A New Method for Pre-election Polling}

\begin{abstract}
This paper outlines a new method for surveys to study elections and voter attitudes. Preelection surveys often suffer from an inability to identify and survey the likely electorate for the upcoming election. We propose a new and inexpensive method to conduct representative surveys of the electorate. We demonstrate the performance of our method in producing a representative sample of the future electorate that can be used to study campaign dynamics and many other issues. We compare pre-election outcome forecasts to election outcomes in seven primary and general election surveys conducted prior to the 2008 and 2010 primary and general elections in three states. The results indicate the methodology produces representative samples, including in low-turnout elections such as primaries where traditional methods have difficulty consistently sampling the electorate. This new methodology combines Probability Proportional to Size (PPS) sampling, mailed invitation letters, and online administration of the questionnaire. The PPS sample is drawn based on a model employing variables from the publicly available voter file to produce a probability of voting score for each individual voter. The proposed method provides researchers a valuable tool to study the attitudes of the voting public.
\end{abstract}


Public pre-election survey forecasts by media and academic survey research centers have generally done well predicting election outcomes (Traugott 2005; Traugott and Wlezien 2009). ${ }^{2}$ However, several obstacles limit their usefulness to scholars interested in studying campaign dynamics and representation. First, because of the challenges associated with cellphone-only households, caller ID, and declining cooperation rates, the rising cost of quality polling means few scholars can afford to conduct pre-election polls using traditional methods (Traugott 2012). Second, these pre-election polls are of limited value for the study of elections and voting. Most public polls are designed to produce media content rather than handle the complex designs and questionnaires needed by scholars to model attitudes and behavior. Finally, the variability in approaches to sampling, screening, and weighting in preelection polling leaves doubts about the best practices scholars should follow. As a response to these challenges, we propose a pre-election polling method that identifies a likely electorate at a modest cost, allows sophisticated survey instruments to study voter attitudes, and avoids the sampling, screening, and weighting pitfalls of many pre-election surveys.

We leverage recent research on survey response, polling technology, and improved voter registration data files to develop a new method of polling voters for an upcoming election. The method involves the creation of a sampling frame that is representative of voters in the upcoming election by drawing a Probability Proportional to Size (PPS) sample. The PPS sample uses a regression model employing variables from the publicly available list of registered voters ("voter file") to produce a predicted probability of voting for each individual voter. We send each selected voter a single invitation letter via U.S. Mail that includes a link and an access code for an online poll. The mailed invitation allows better

\footnotetext{
${ }^{2}$ There have been a few notable exceptions, such as the 2008 New Hampshire Democratic primary (Traugott \& Wlezien 2009).
} 
coverage of the sampling frame than is possible with telephone, in-person, email, or other survey recruitment methods. Furthermore, administering the survey online allows sophistication and flexibility in questionnaire design (such as branching, skips, experiments, and multimedia use).

This method facilitates more extensive study of campaign dynamics and representation. The relatively low cost of our method should allow scholars to design and field surveys about an array of research questions about which data is not currently collected. For example, our method can be used to survey states, congressional districts, and local elections that vary from national trends. These surveys will likely provide new insights about the links between voter attitudes during the campaign and the policy making activities of their elected representatives. In particular, the method produces representative samples for primary elections for which little data is currently available to scholars, despite playing a growing role in selecting elected officials and shaping their actions in the context of high polarization and heavily gerrymandered districts.

We present data from seven pre-election surveys that cover a variety of electoral situations across primary and general elections in 2008 and 2010 in Utah, Colorado, and Florida. The results indicate a close correspondence between the survey data and actual election results. We conclude with a discussion of the contribution this methodology can make to understanding political and social behavior and some ideas about how the methodology could be altered to allow study of additional research questions, such as more extensive study of non-voters or studying the attitudes and motivations of campaign contributors. 


\section{Coverage Error in Pre-election Polling}

The major challenge with pre-election polling rests in constructing a sampling frame for a target population of an event that has not yet occurred. Specifically, a pre-election survey must construct a sampling frame of potential voters that accurately reflects a target population of future actual voters. The difficulty of identifying who will vote prior to an election makes accurate pre-election polling one of the most difficult tasks in political methodology. One expert on pre-election surveys concludes, "one of the weakest design features of most [pre-election] polls is their inability to identify correctly likely voters, especially in low turnout elections" (Crespi 1988, 178). Coverage error occurs when the sampling frame does not correspond well with the target population. Weisberg defines it as the "mathematical difference between a statistic calculated for the population studied and the same statistic calculated for the target population" (Weisberg 2005, 205). ${ }^{3}$

Publicly available pre-election polling has typically been done by telephone with random digit dialing (RDD) samples. RDD's strength is approximating true random sampling of the general population, so it should produce relatively unbiased estimates of the general population (Yeager et al. 2011). However, RDD's weakness in pre-election polling is that the target population of people who will vote in the upcoming election is substantially different than the RDD sampling frame of all phone numbers.

Pre-election RDD surveys use screening questions to attempt to reduce this coverage error. These questions often identify "likely voters" based on deterministic responses that include or exclude a respondent in the survey (Burden 1997; Crespi 1988; Perry 1960; 1979).

\footnotetext{
${ }^{3}$ Determining likely voters in a telephone survey extends the coverage problem to one of within-unit coverage because the sampling unit for a typical telephone survey is the household and not the individual voter (Lavrakas 1993, 118).
} 
However, there is a well-known problem with over-reporting of voting due to social desirability effects and misreporting by respondents who vote irregularly (Ansolabehere \& Hersh 2012; Rogers \& Aida 2013; Petrocik 1991; Silver, Anderson, \& Abramson 1986, 615). In addition, recent research using vote validation of several large-scale surveys has found that under-reporting of voting also occurs more frequently than previously understood (Ansolabehere \& Hersh 2012; Rogers \& Aida 2013).

Even if responses to "likely voter" screens were accurate, excluding unlikely voters fails to account for a sizable portion of the actual electorate. Deterministically selecting individual likely voters to represent the future electorate is an inverse ecological fallacy: Although individuals may have a low probability of voting, collectively these individuals may cast a substantial share of the votes in the upcoming election. This problem increases as overall turnout levels decline. If the attitudes of voters with a low individual likelihood of voting are different from the attitudes of individuals with a high likelihood of voting, the deterministic approach generates coverage error because it excludes voters based on screening questions. (See the online Supplemental Materials for further discussion).

\subsection{Using Predicted Probability of Voting to Reduce Coverage Error}

Probabilistic approaches to selecting respondents for pre-election surveys have less risk of coverage bias because they include the entire population, with sampling weighted by each individual's predicted probability of voting (Burden 1997). The challenge for a probabilistic approach is the method for creating the probabilities of voting. Using selfreports to create these voting probability weights is based on the idea that revealing an intention to engage in an activity is the best predictor of future behavior (Fishbein and Ajzen 1975). However, self-reports are also biased by social desirability and correlation between 
responding to the survey and voting. Thus, probabilistic approaches using survey responses may reduce coverage error over deterministic approaches, but they do not eliminate the risk of coverage error. ${ }^{4}$

Green and Gerber (2006) propose a probabilistic selection method for pre-election surveys. The method relies on objective reports of individual-level past voting from public voting records to pre-stratify the sample by probability of voting and proportion of the electorate. Green and Gerber separate the list of registered voters into five strata based on past voting history and then randomly sample voters from each stratum in proportion to the expected share of the electorate in each stratum. The expected share of the electorate is based on the distribution in similar past elections. In a comparison of traditional RDD methods with their Registration-Based Sampling (RBS) telephone surveys, Green and Gerber found that the RBS sampling method performs as well or better in terms of its predictive accuracy of election outcomes. In other words, RBS reduces coverage error.

Instead of Green and Gerber's small number of strata based on vote history, we develop a model to predict the probability of voting in the upcoming election for each individual voter using vote history, partisan affiliation, age, gender, and other demographic characteristics from the voter file. We then use this model to draw probability proportionate to size (PPS) samples. ${ }^{5}$ PPS sampling is used to select primary sampling units (PSU), with higher probabilities assigned to PSU's with more “elements.” In our survey methodology,

\footnotetext{
${ }^{4}$ For further discussion of probabilistic likely voter models, see Burden 1997; Juster 1960; Traugott \& Tucker 1984; Petrocik 1991; Voss, Gelman, \& King 1995; Hoek and Daves 1997; Freedman \& Goldstein 1997.

${ }^{5}$ See online Supplemental Materials for discussion of PPS sampling where the total sample size is determined before sampling rather than Probability Proportionate to Prediction sampling where the total sample size is unknown before sampling.
} 
the PSU is the individual voter. The "elements" for each voter that determine the probability of selection is the predicted probability of voting in the upcoming election. The probability of selecting any given PSU is calculated by considering the number of elements in the PSU compared to the overall population of elements in PSUs. (A rigorous derivation of these probabilities is shown in Lohr (2010). See online Supplemental Material for further discussion). In other words, voters with higher probabilities of turning out are more likely to be sampled for our surveys. As long as the predictive model performs well, this approach has enormous potential to reduce coverage error because it creates a sampling frame that accurately reflects the target population of voters in the future election.

\subsection{Low Response Rates and Non-Response Error}

Although conventional wisdom long held that high response rates lead to reduced non-response bias and higher accuracy, recent research suggests that response rates are only weakly related to bias and accuracy. Low response rates have not led to significant levels of bias in most surveys (Groves 2006; Keeter et al. 2006; Keeter et al. 2000; Pew Research Center 2012), including surveys administered online or by mail that typically have very low response rates (Atkeson et al. 2011; Yeager et al. 2011; Visser et al. 1996).

In some cases, efforts to increase response rates actually increase non-response error because additional effort fails to yield the type of respondents who are missing (Dillman et al. 2009; Peytchev, Baxter, and Carley-Baxter 2009)). In post-election surveys in 2006 in Colorado and New Mexico, Atkeson et al. (2011) used mailed invitations to a simple random sample of registered voters for a survey administered online. They found that, despite low response rates, the online respondents closely resembled the sampling frame. However, offering potential respondents an additional option to complete a questionnaire by mail 
increased the response rate but made their sample less representative than only using the online respondents.

Our methodology relies on the voter's interest and motivation to respond to the online survey to help identify the future electorate and thereby reduce coverage error. In general, Groves and Peytcheva (2008) find that the relationship between response rate and response bias is weak when the causes of survey participation are correlated with the survey topic. The combination of a mailed invitation to participate with an online survey requires more effort from the respondent than traditional telephone or in-person interviewing methods. However, similar burdens accompany the act of voting, so even with low response rates, respondents are more likely to be voters (Visser et al. 1996). An assumption in our PPS sampling method is that the voters selected with low individual probability of voting who make the effort to complete the survey are representative of people with low scores who will actually show up at the polls. In short, the burden of completing the survey online mimics the burden of voting and acts as a valuable screening mechanism to improve the similarity between voters and respondents. Since the screening mechanism is based on the potential respondents' actual behavior, rather than on self-reports of intention or attitudes, this should be a more reliable indicator of future behavior and help to reduce coverage error.

\subsection{Probability Samples Administered Online}

Administering surveys online offers potential advantages including lower data collection costs, sophisticated questionnaire design, and elimination of interviewer effects (Alvarez et al. 2003; Berrens et al. 2003). However, it is important to distinguish online panel surveys - that rely on samples of volunteers recruited to participate in multiple online surveys - from simply using the Internet to administer a survey instrument to a probability 
sample recruited off-line from the full population of voters. While there is considerable debate about bias in online panel surveys using non-probability samples (e.g., Baker et al. 2013; Stephenson \& Crete 2011; Baker et al. 2010; Chang \& Krosnick 2009; Malhotra \& Krosnick 2007; Sanders et al. 2007; Dillman \& Christian 2005; Alvarez et al. 2003; Couper 2000), administering surveys to probability samples of registered voters via the Internet does not hold the same concerns (Atkeson \& Tafoya 2008; Atkeson et al. 2011). In short, critiques of online panel surveys using non-probability samples do not apply to our proposed methodology.

Administering a survey online raises important questions about Internet access and use. Internet access patterns in the general population closely resemble the differences between the general population and voters. Chang and Krosnick (2009) find that an online probability sample showed higher levels of partisanship and political knowledge than the general population. However, partisanship and political knowledge correlate strongly with voter turnout (Larcinese 2007), especially in low-salience elections. If an online probability sample is biased towards higher levels of education, income, and other socio-economic differences, this may improve its accuracy because these are precisely the same characteristics that distinguish voters from nonvoters.

Scholars interested in the dynamics of elections and attitude formation will appreciate the advantages of online survey administration. First, lower costs may make it possible for researchers to conduct multiple waves or increase sample size. Second, online administration makes it possible to ask more sensitive questions regarding political attitudes, determinants of vote choice, and other topics. Third, online administration reduces or removes acquiescence, satisficing, and social desirability bias that occurs when an interviewer is present for phone and in-person interviews (Chang \& Krosnick 2009, 2010; Dillman et al. 
2009; Groves \& Peytcheva 2008; Dillman \& Christian 2005). Finally, online survey

administration facilitates complex branching, skipping, and ordering of items, especially for survey experiments, and allows adding visual and audio elements to questionnaires. All of which are helpful in the study of persuasion, vote choice, and policy preferences.

\section{Implementing Our Methodology}

We conducted seven pre-election surveys to test this methodology, with each survey fielded during the week prior to Election Day. The seven surveys were: the 2008 Utah Republican primary (3rd Congressional District only), the 2008 Utah general election, the 2010 Colorado Republican primary, the 2010 Colorado Democratic primary, the 2010 Utah Republican primary, the 2010 Utah Democratic primary (2nd Congressional District only), and the 2010 Florida general election. In total, we surveyed preferences in eighteen different races.

We present two of the seven surveys to illustrate our method and results: the 2010 Colorado Republican primary and the 2010 Florida general election. We selected these two surveys because: a) they cover a primary and a general election; b) they have multiple races to assess pre-election forecasts; c) Florida presents unique challenges from a three way US Senate race and non-partisan ballot measures; and d) they are recent, competitive elections. Table 1 describes the races polled in each of the seven surveys. All seven surveys performed well. The online Supplemental Materials contain results, test statistics, and distributions described below for all seven surveys.

[Table 1 Here] 


\subsection{Predicting Probability of Turnout for Individual Voters}

We first predicted each registered voter's probability of voting in the upcoming election using a model with data from each state's publicly available voter file. These files contain information regarding registration status, partisan affiliation, age, gender, address, political jurisdiction, and previous voting history for every registered voter in each state. The files are updated every election and include whether or not each person in the file turned out to vote. Additionally, any changes in a person's registration status (i.e. first-time registration date, change of party affiliation, legislative districts) are updated. ${ }^{6}$ With this information, we use logistic regression to estimate a likely voter model specific to the election and jurisdiction of each survey. Our predictive modeling relies on the most recent past election that resembles the upcoming election as the dependent variable. ${ }^{7}$

\footnotetext{
${ }^{6}$ States with Election Day registration require a slightly different data file including registered voters and potentially eligible citizens. Commercial voter data firms and both major political parties maintain these files in Election Day registration states, so they are available.

${ }^{7}$ Ideally our predictive models would use the list of registered voters at the time of the previous election. Unfortunately, this data was not available from public sources. We use voters on the current file who were registered prior to the election used for modeling. This biases the predictions upwards since non-voters are more likely to be removed. However, only a small share of non-voters is removed over the 2-4 year periods in question since federal law restricts when voters can be removed. The ROC curves of predictive performance in Supplemental Materials Figure S2 confirm that the bias in our models must be small. Finally, we note that this concern may be mitigated in the future, as commercial firms and the political parties have begun to archive prior version of the voter file that could be used to for this stage of generating predicted probabilities.
} 
Selecting the appropriate historical election for each predictive model requires some judgment. ${ }^{8}$ The choice is clear in many cases, especially for even-year general elections. Turnout patterns usually remain quite consistent across presidential general elections and across mid-term general elections. Primaries and other elections, where contestation and interest alter turnout patterns, require more judgment about what past election is most similar to the upcoming election. For the 2010 Colorado Republican primary, we used the 2008 Colorado Republican primary election as the dependent variable. ${ }^{9}$ In the 2010 Florida general election, we used the 2006 general election. In situations where researchers are uncertain about which past election to use to develop the predictive model, more complex approaches such as model averaging could be used. Moreover, the worst case for scholars studying voter attitudes (rather than making short-term election outcome predictions) is applying small weights to correct for unusual deviations in turnout between similar elections.

Our dependent variable in each model is a dichotomous indicator of whether or not the citizen voted in the historical election that resembles the upcoming election of interest. The online Supplemental Materials provide the rationale for the selection of the historical election, a description of each variable used in the different models, estimated coefficients, standard errors, and other model statistics. In general, each model reflects the following estimation.

\footnotetext{
${ }^{8}$ Current probabilistic approaches such as the Green and Gerber RBS voter file based probabilistic method and survey response based probabilistic method (described above) also rely on the researcher correctly selecting a comparable past election to determine the probabilities for selection.

${ }^{9}$ The sampling frame for primary elections requires careful attention to which voters are eligible to vote, given the different election rules for each state. See the online Supplemental Material for a discussion of the procedure used to identify eligible voters in Colorado.
} 
Predictive Turnout Model Framework

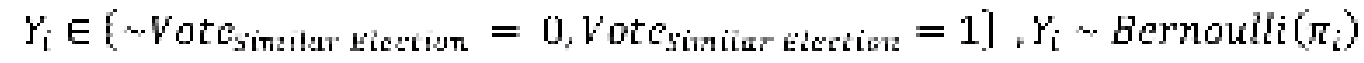

$$
\begin{aligned}
& \operatorname{logit}\left(\pi_{i}\right)=\alpha+\beta V_{i}+\gamma+\gamma R_{i}+\tau D_{i}+v I_{i}+\varepsilon_{1}
\end{aligned}
$$

where $\mathrm{Y}_{\mathrm{i}}$ is a dichotomous variable indicating whether or not the respondent voted in a previous election. $\mathrm{V}_{\mathrm{i}}$ is a vector of variables that measure past voting behavior in general elections, primary elections, and off-year elections. $\mathrm{R}_{\mathrm{i}}$ is a vector of variables that measure the time since an individual first registered to vote or most recently updated their registration status. $D_{i}$ is a vector of variables that measure demographic characteristics potentially correlated with voting such as age, party registration, and gender. Finally, $\mathrm{I}_{\mathrm{i}}$ is a vector of interaction terms of some of the previously mentioned variables. For example, in primary elections in which both partisans and independents are allowed to vote, we include an interaction between partisan registration and previous turnout to allow for a different effect of past turnout between registered partisans and independents. In all cases, the independent variables in each model come from the voter file. When developing the model, we used only the subset of voters registered prior to the previous election. We adjusted the independent variables for that election (e.g., calculating age at the time of the election used as the dependent variable). ${ }^{10}$ Our predicted probability of voting in the upcoming election is calculated using the coefficients from the model of the historical election and current demographic information. This procedure produces a predicted probability of voting for

\footnotetext{
${ }^{10}$ Malchow (2008, chapter 11) describes a similar process of modeling turnout used by political consultants.
} 
every currently registered voter, including those who entered the voter file after the historical election. $^{11}$

We will not discuss the coefficients and their respective statistical significance because any regression model with as many observations as we have (often several million) will produce extremely small standard errors. As expected, past voting has the strongest relationship to future behavior in each model. ${ }^{12}$ Further, the signs of the other coefficients are in the expected direction, and their magnitude is consistent with past research on correlates of voter turnout.

The distributions of individual voter turnout probabilities for the registered voters eligible for each election are shown in the first row of Figure 1. As expected, the distributions of probabilities in the Colorado primary are skewed to low values compared to the Florida general election. In the general election, when turnout is significantly higher than in the primary election, the distribution of predicted probabilities is much more uniform.

[Figure 1 Here]

\footnotetext{
${ }^{11}$ The out of sample predictions for people not registered prior to the historical election include two groups of people: 1) newly registered voters (previously ineligible due to age or citizenship) and 2) registered voters who have moved into the jurisdiction for the first time after the historical election used in the model. The predicted probabilities of voting for the latter group may be biased downward because we are unable to count the number of previous elections in which they voted. Therefore, these new registrants may be slightly under-sampled. However, they constitute a very small proportion of eligible voters and are unlikely to have systematically different attitudes, so any bias is likely to be small.

${ }^{12}$ Our models utilize six to eleven past elections grouped into indices of general, primary, and municipal elections to minimize any potential influence from unusual turnout, poor record-keeping or other issues in past voting data.
} 


\subsection{Probability Proportionate to Size Sampling}

The predicted probabilities of voting in the upcoming election are the basis for our Probability Proportionate to Size (PPS) sampling. With PPS sampling, voters with a higher predicted probability of voting have a higher likelihood of being selected for our sample. If our vote probability predictions are correct, then PPS will produce a sample that reflects the actual electorate in the upcoming election. To draw our sample, we use the "gsample" program developed for Stata (Jann 2006). ${ }^{13}$

Returning to Figure 1, the PPS samples (Row 2) are shifted to the right compared to the population of registered voters (Row 1), but the PPS samples still include registered voters across the entire spectrum of vote probability for both primary and general elections. The shift for the PPS sample is more pronounced in primaries because many voters have a very low probability of turning out. In the Colorado Republican primary election sample, registered voters (Row 1) are heavily skewed to the right, but in the PPS sample the concentration of those with almost no chance of voting in the primary disappears and the PPS sample distribution is close to uniform with only a bump among high predicted probability voters (Row 2). In the Florida general election sample, registered voters are spread across the predicted probability spectrum with a plateau on the left (low probability) and a small peak on the far right (high probability). The PPS sample in Florida has a

\footnotetext{
${ }^{13}$ In the 2008 Utah primary and general election surveys, a portion of our sample was selected using PPS and a portion was selected using simple random sampling (SRS) to compare the effects of each approach. See the online Supplemental Materials for an analysis and discussion of the differences between the PPS and SRS samples and polling results from each sampling method. As hypothesized, we found PPS sampling provides a sample more representative of the electorate. As a result, we used PPS sampling for the five other polls we conducted.
} 
significantly smaller proportion of low probability voters and a much higher peak among high probability voters.

\subsection{Survey Recruitment}

We sent a single letter to each sampled individual, inviting participation in the survey by accessing a website. The invitation count for each survey is listed in Table 1 Column 3. The invitation letters were the sole contact to recruit respondents to participate in the survey. There was no pre-notification ${ }^{14}$ and no reminders to complete the survey. There was also no online or panel recruitment. The letters were mailed 7-10 days prior to the respective Election Day by first class U.S. Mail. Row 5 in Table 1 reports the date on which we mailed the letters for each survey. The invitations for the Colorado, Florida, and Utah surveys were sent from the University of Colorado-Boulder; the University of Miami in Coral Gables, FL, and Brigham Young University in Provo, UT, respectively. (See the online Supplemental Materials for examples of invitation letters.)

The online survey instrument was activated the day the letters were mailed and was closed at midnight on the Monday prior to Election Day. Each letter contained a unique ID code assigned to each respondent that they were required to input to take the survey. This ensured that only invited respondents completed the survey and prevented anyone from completing it multiple times. Each of the surveys asked various questions regarding candidate preference for several offices, issues in the campaign, and demographic questions. (Copies of the survey instruments are available upon request.)

\footnotetext{
${ }^{14}$ See Mann (2005) for a discussion of the impact of pre-notification letters on the accuracy of pre-election surveys.
} 


\section{Results and Accuracy}

\subsection{Survey Structure and Modes of Voting}

In each survey, respondents were first asked whether or not they had already voted via absentee or early voting. If they had, they were directed to a question that asked for whom they voted. ${ }^{15}$ Respondents who told us they had not yet voted were asked to indicate on a 10 point scale how likely it was that they would vote in the upcoming election. Voters who selected "0, no chance I will vote" were directed to demographic questions at the end of the survey. Voters who chose anything besides " 0 " were then asked for whom they planned to vote in the races of interest. In the Colorado survey 7.5 percent of the sample completed the survey while the response rate in the Florida poll was 5.1 percent. ${ }^{16}$

\subsection{Accuracy of Predictive Turnout Models}

We first look at how well our models predicted actual turnout among all registered voters following each election. ${ }^{17}$ A ROC curve plots the sensitivity (the rate of true positives) vs. 1-specificity (the rate of false positives) for models of binary outcomes as the model's predictions are tested while varying the cut-point from 0 to 1 . The area under the curve is a

\footnotetext{
${ }^{15}$ This question included an option for "don't remember/did not vote in this election." Our forecasts exclude the very small number of voters who said they had already voted, but indicated that they either could not remember who they voted for or did not vote in that specific race.

${ }^{16}$ We calculate the response rate using the formula for AAPOR Response Rate 1 (www.aapor.org/Standard_Definitions2.htm).

${ }^{17}$ We rely on the individual level vote history from state and county election administrators because this is the best available data on voting behavior. It is possible that this legal record of voter participation contains inaccuracies, but these are likely to be very small and to occur in both directions (Ansolabehere and Hersh 2012).
} 
measure of the accuracy of the model. A model with no false negatives and no false positives (perfect predictions for every individual) has the maximum area of 1 . Therefore, ROC curve areas close to 1 indicate a model that accurately predicts individual voter turnout.

All our models preformed well at predicting actual turnout. The area under the ROC curve was 0.91 in the Colorado Republican primary model and 0.84 in the Florida general election model. Moreover, the curves appear to be quite smooth, indicating that each model performs well across the entire range of predicted probabilities of voting. (See the online Supplemental Materials Figure S2 for the ROC curves for all seven surveys).

Ideally, coverage error is minimal and those who responded to our surveys are representative of those who voted in the upcoming election. In Row 4 of Figure 1, we report the distribution of actual turnout, based on post-election public records of individual-level turnout. Before looking at our samples or respondents, we note that the distribution of actual voters (Row 4) is shifted substantially to the right of the population of all registered voters (Row 1). We confirm that our PPS sampling methodology, based on the estimated probability of voting, matches the actual electorate by comparing Row 4 with our survey sample (Row 2).

The goal of our methodology is a sample of survey respondents representative of the likely electorate. Therefore, we also compare the distribution of survey respondents (Row 3) to the distribution of actual voters (Row 4). Despite less detailed histograms because of the smaller number of respondents, it is clear that the distribution of respondents closely resembles actual turnout. The respondents to the 2010 Colorado Republican primary survey are skewed a bit too far to the right, but this occurs because our model of turnout in a low salience election is more likely to have Type II errors. It is worth noting again that we do not exclude low-probability voters from responding. Even though each of these registered voters 
is individually unlikely to vote, many of them do turn out. In the aggregate they comprise a substantial portion of the electorate, so a survey needs to include them.

\subsection{Assessing Performance: Poll Forecasts and Election Outcomes}

The ultimate assessment of potential coverage error is to assess the predictive accuracy of the method by comparing forecasts from our surveys to the actual election results. Figure 2 displays these results in both surveys. The vertical axis includes all contests surveyed in each election. For each race we display our pre-election forecast with corresponding 95 percent margin of error for the winner of each race and the actual percentage of the vote the winner obtained. In every case, the actual result is contained within our survey's margin of error. (The online Supplemental Material reports the same pattern also holds in the remaining five surveys).

[Figure 2 Here]

Figure 2 also shows the accuracy of our methodology compared to publicly available telephone polls that were conducted while our poll was in the field. ${ }^{18}$ Looking at the predicted vote share for the winner in each race, our survey was the most accurate poll in four races (Colorado Governor, Colorado Senate, Florida Senate, and Florida Chief Financial Officer) and the median poll in the Florida Amendment 6 race. Our forecast was

\footnotetext{
${ }^{18}$ We used public polls available at www.realclearpolitics.com. If www.realclearpolitics.com did not report polls for a particular contest, we identified public polls via a standard Google search. Figure S3 in the online supplemental materials reports this comparison for all seven surveys. We were unable to locate any polls for Amendment 1 in Florida's 2010 general election or Utah Attorney General in 2008. Data for the public polls used in Figure 2 and Figure S3 is available in the online Supplemental Materials Tables S2 and S3. When these polls included an "undecided" option, we allocate these votes to candidates proportionately.
} 
slightly less accurate in the Florida attorney general race. In the Florida Governor's race, our survey was in the middle of the pack in terms of absolute difference from the outcome $\left(4^{\text {th }}\right.$ of seven surveys), but had the largest under-prediction of the winner's vote share (49 percent). ${ }^{19}$ Across all seven surveys in 2008 and 2010, in 60 percent of the races, our methodology outperformed publicly available polls using traditional phone interviewing techniques, and effectively tied public polls in an additional 20 percent of the races. The performance of our forecasts across all contests suggests that our methodology is accurate in primary elections, general elections, referenda, and competitive races. Our methodology is accurate in different regions of the country, in races that are highly salient, and in low salience "down-ballot" races. Our methodology achieved this performance by improving coverage, eliminating interviewer bias, and administering sophisticated questionnaires - all while dramatically reducing survey costs.

\section{Conclusion}

This paper contributes to survey research methodology by drawing from disparate branches of knowledge to build a reliable method of pre-election polling. Parts of our method are familiar to scholars but other parts are innovative in leveraging new and better data, technology, and social science research. First, the method incorporates a basic finding in political science regarding voting behavior: individuals with higher levels of interest and knowledge tend to participate in politics at greater rates. These individuals also have key characteristics that make them more likely to respond to pre-election surveys. Second,

${ }^{19}$ Since we are assessing pre-election forecasts about primaries, multi-candidate races (2010 Florida Senate race), and ballot measures, we cannot use Martin, Traugott and Kennedy's (2005) standard "Predictive Accuracy" measure for comparing pre-election survey performance, since this measure is applicable only in two party candidate contests. 
utilizing PPS sampling techniques creates a sampling frame of voters in the election of interest that has otherwise been difficult to achieve in pre-election polling. The PPS sample along with recruiting participation via mailed letters allows better coverage of the sampling frame of voters than RDD sampling and other modes of interviewing. The formula for drawing the sample is also transparent and replicable. Finally, the method makes use of the increasing accessibility and accuracy of voter registration lists that provide a wealth of information to assemble better sampling frames.

The 2012 Presidential election provided a powerful reminder of the importance of methodology in drawing accurate inferences about the future electorate. The Romney Presidential campaign discovered their survey methodology to identify likely voters was based on faulty assumptions (Scheiber 2012). Consequently, the Romney campaign strategy was based on incorrect inferences about the attitudes of the electorate. Scholars should take extra caution to ensure similar faulty assumptions in survey methodology do not lead to incorrect understandings of attitudes among the voting electorate.

Establishing the accuracy of our pre-election polling method is an essential first step to making it more widely acceptable for research on campaign dynamics and representation. Nevertheless, further research on our method remains. Our surveys were conducted in elections where other surveys do not have sufficient data or are unavailable making more detailed comparisons impossible for now. The consistent forecast accuracy across multiple election contests strongly suggests validity of our method, but conducting parallel analyses from parallel surveys using our method and more traditional methods would still be helpful. ${ }^{20}$ Comparisons of substantive empirical relationships would produce different results

\footnotetext{
${ }^{20}$ For example, an ideal assessment of our method against a more traditional method would include a voter validation effort for both surveys. Our method makes turnout validation
} 
if our method is more representative of the actual electorate. Indeed, we expect these differences to be similar to the differences found by Ansolabehere and Hersh (2011) when comparing analyses of self-reported voters to validated voters.

The potential usefulness of our method also extends well beyond pre-election forecasting. For example, the methodology can be used in non-election periods to provide low cost and accurate data to facilitate research on a wide array of questions about topics where data are currently scarce or unavailable. ${ }^{21}$ In particular, the method enables jurisdiction-specific research to fill in gaps about the considerable heterogeneity in policy and politics across the United States. Research on campaign dynamics and representation in Senate, Congressional, state-level and local-level elections is often limited by inadequate data. Since elected officials are most responsive to the citizens who cast ballots, the ability to survey their electorate in their district or state allows researchers to better study the links between the policy choices of politicians and the attitudes of voters they care about most (Bartels 1991, Butler and Nickerson 2011, Gilens 2012). The method has the largest advantage over traditional methods in local off-year elections or primary elections about which scholars have relatively little to say despite their increasing importance in American elections and policy-making.

One valuable use of our method is clear to us because it was the motivation for developing the method: replacing exit polling for pre-Election Day voters, especially for ballots cast by mail. In states like Oregon, Washington, and Colorado, where all voters are straightforward and inexpensive. The data to compare our method with more traditional surveys conducted in the same elections are not available.

${ }^{21}$ For example, the surveys presented here have already been used in published work about the Tea Party movement that includes a focus on estimating effects in primary elections (Karpowitz, Monson, Patterson, and Pope 2011; Frei, Monson, Murray, and Patterson 2012). 
sent mail ballots, our method allows scholars to collect data on attitudes proximate to the act of voting similar to exit polling. In states with high mail ballot use, the method can be adapted to supplement traditional exit polling of in-person voters - or used to replace exit polling for all types of voters. The method can also be deployed to study states and districts not covered by the media industry's National Election Pool exit polls. ${ }^{22}$

This method could also be altered to study other topics of interest. First, PPS sampling on the inverse of the voting probability could be used for studies of nonparticipants with larger samples of low-propensity voters and non-voters. Surveys of nonvoters would provide a richer understanding of attitudes of non-participants and facilitate survey experiments on how these voters might be mobilized. Second, a valid pre and postelection panel can be constructed by gathering emails at the end of the pre-election survey to facilitate post-election contact or by mailing another invitation to the post-election wave. ${ }^{23}$ Online administration of the survey eliminates attrition due to the inability of an interviewer to contact a panel respondent in limited windows of availability. Third, the method can be altered to reach other difficult to identify populations of interest to political scientists. For example, the method has been adapted to survey campaign contributors based on public records of past contributions (Barber 2013). Finally, the method permits researchers to

\footnotetext{
${ }^{22}$ We have worked together with National Election Pool officials to conduct a small pilot using this method in a Nevada special election where they did not have the resources to deploy a full exit poll.

${ }^{23}$ This has already been tested in a recent congressional campaign district survey (Karpowitz, King-Meadows, Monson, and Pope 2013). The pre-election survey produced 1,095 completed surveys of which 733 , or 67 percent, agreed to share an email address for a brief post-election survey. Seventy seven percent of the wave 1 respondents $(567 / 733)$ completed the post election survey for an overall post election reinterview rate of 52 percent
} $(567 / 1,095)$ 
perform experiments on a representative sample in the hopes of identifying causal mechanisms that shape individual and public opinion. ${ }^{24}$

Due to changes in technology, survey research has undergone dramatic transformation over the last two decades that brings new challenges to survey methodology and new opportunities for research on campaign dynamics and representation. From the reduction in households reachable on landline phones to the development of new modes of survey administration, scholars interested in elections, voting, and political attitudes must adapt their survey methodology to accommodate this changing landscape. For survey research to continue to provide accurate insights about elections and attitude formation, scholars will need to exploit the knowledge of social science disciplines and couple them with electronic databases, new developments in sampling, and survey administration.

\footnotetext{
${ }^{24}$ For example, the surveys presented here have already been used to experimentally test name generators used in political network analysis (Sokhey and Djupe 2013) and for an experiment involving racial stereotypes (Karpowitz, King-Meadows, Monson, and Pope 2013).
} 


\section{References}

Alvarez, R. Michael, Sherman, Robert P., and VanBeselaere, Carla. 2003. "Subject Acquisition for Web-Based Surveys.” Political Analysis 1:23-43.

Ansolabehere, Stephen and Eitan Hersh, 2012. "Misreporting, Sample Selection, and Participation.” Political Analysis 20: 437-459.

Atkeson, Lonna R. and Lorraine M. Tafoya, 2008. "Surveying Political Activists: The Effectiveness of a Mixed Mode Survey Design.” Journal of Elections, Public Opinion \& Parties 18:367.

Atkeson, Lonna, Alex Adams, Lisa Bryant, Luciana Zilberman, and Kyle Saunders. 2011. "Considering Mixed Mode Surveys for Questions in Political Behavior: Using the Internet and Mail to Get Quality Data at Reasonable Costs." Political Behavior 33:161178.

Baker, Reg, J. Michael Brick, Nancy A. Bates, Mike Battaglia, Mick P. Couper, Jill A. Dever, Krista J. Gile, Roger Tourangeau. 2013. "Report of the AAPOR Task Force on Non-Probability Sampling." May 2013 (updated June 22, 2013). Available at: http://www.aapor.org/Reports1.htm [Accessed September 18, 2013].

Baker, Reg, Stephen J. Blumberg, J. Michael Brick, Mick P. Couper, Melanie Courtright, J. Michael Dennis, Don Dillman, Martin R. Frankel, Philip garland, Robert M. Groves, Courtney Kennedy, Jon Krosnick, Paul J. Lavrakas, Sunghee Lee, Michael Link, Linda Piekarski, Kumar Rao, Randall K. Thomas, and Dan Zahs. 2010. "AAPOR Report on Online Panels." Public Opinion Quarterly 74:711-81.

Barber, Michael J. 2013. "Ideological Donors, Contribution Limits, and the Polarization of State Legislatures". Presented at the annual meeting of the American Political Science Association.

Bartels, Larry. 1991. "Constituency Opinion and Congressional Policy Making: The Reagan Defese Buildup.” American Political Science Review 85: 457-474.

Berrens, Robert P., Bohara, Alok K., Jenkins-Smith, Hank, Silva, Carol, and Weimer, David L. (2003). "The Advent of Internet Surveys for Political Research: A Comparison of Telephone and Internet Samples." Political Analysis 11:1-22.

Burden, Barry. 1997. "Deterministic and Probabilistic Voting Models." American Journal of Political Science 41:1150-69.

Butler, Daniel and David Nickerson. 2011. "Can Learning Constituency Opinion Affect How Legislators Vote? Results from a Field Experiment.” Quarterly Journal of Political Science 6:55-83 
Chang, LinChiat and Jon Krosnick. 2009. "National Surveys via RDD Telephone Interviewing Versus the Internet: Comparing Sample Representativeness and Response Quality.” Public Opinion Quarterly 73:641-678.

Couper, Mick P. 2000. "Web Surveys: A Review of Issues and Approaches.” Public Opinion Quarterly 64:464-94.

Crespi, Irving. 1988. Pre-election Polling: Sources of Accuracy and Error. New York: Russell Sage Foundation.

Dillman, Don A., and Leah M. Christian. 2005. "Survey Mode as a Source of Instability in Responses Across Surveys.” Field Methods 17:30-52.

Dillman, Don A., Glenn, Phelps, Robert Tortora, Karen Swift, Julie Kohrell, Jodi Berck and Benjamin L. Messer. 2009. "Response Rate and Measurement Differences in MixedMode Surveys using Mail, Telephone, Interactive Voice Response (IVR) and the Internet." Social Science Research 38:1-18.

Fishbein, Martin and Icek Ajzen. 1975. Belief, Attitude, Intention, and Behavior. Reading, MA: Addison-Wesley Publishing.

Freedman, Paul and Ken Goldstein. 1997. "Building a Probable Electorate from Pre-election Polls: A Two Stage Approach.” Public Opinion Quarterly 60:574-87.

Frei, Matthew D., J. Quin Monson, Leah Murray, and Kelly D. Patterson. 2012. "Tea for Only Two: The Ousting of Utah Senator Robert Bennett." In William J. Miller and Jeremy D. Walling, eds. Tea Party Effects on 2010 U.S. Senate Elections: Stuck in the Middle to Lose. Lanham, MD: Lexington Books.

Green, Donald P., and Alan S. Gerber. 2006. "Can Registration-Based Sampling Improve the Accuracy of Midterm Election Forecasts?” Public Opinion Quarterly 70:197-223.

Gilens, Martin. 2012. Affluence and Influence: Economic Inequality and Political Power in America. Princeton, NJ: Princeton University Press.

Groves, Robert M. 2006. "Non-response Rates and Non-response Bias in Household Surveys" Public Opinion Quarterly 70:646-75.

Groves, Robert M., and Emilia Peytcheva. 2008. “The Impact of Nonresponse Rates on Nonresponse Bias.” Public Opinion Quarterly 72:167-189.

Hoek, Janet and Robert P. Daves. 1997. "Turnout Prediction: A Comparison of Methodologies." Presented at the annual meeting of the American Association for Public Opinion Research, Norfolk, VA. 
Jann, B. 2006. "gsample: Stata module to draw a random sample." Available at: http://ideas.repec.org/c/boc/bocode/s456716.html. [Accessed February 8, 2012].

Juster, F. Thomas. 1960. "Prediction and Consumer Buying Intentions." American Economic Review 50:604-22.

Karpowitz, Christopher F., Tyson King-Meadows, J. Quin Monson, and Jeremy C. Pope. 2013. "Carrying Many Credentials: Partisan, Racial, and Religious Dynamics in the Utah Fourth District". Presented at the annual meeting of the Midwest Political Science Association.

Karpowitz, Christopher F., J. Quin Monson, Kelly D. Patterson, and Jeremy C. Pope. 2011. "Tea Time in America? The Impact of the Tea Party Movement on the 2010 Midterm Elections" PS: Political Science \& Politics 44:303-309.

Keeter, Scott, Carolyn Miller, Andrew Kohut, Robert M. Groves, and Stanley Presser. 2000. "Consequences of reducing nonresponse in a national telephone survey". Public Opinion Quarterly, 64:125-148.

Keeter, Scott, Courtney Kennedy, Michael Dimock, Jonathan Best and Peyton Craighill. 2006. "Gauging the Impact of Growing Non-response on Estimates from a National RDD Telephone Survey.” Public Opinion Quarterly 70:759-779.

Larcinese, Valentino. 2007. "Does Political Knowledge Increase Turnout? Evidence from the 1997 British General Election.” Public Choice 131: 387-411.

Lavrakas, Paul J. 1993. Telephone Survey Methods: Sampling, Selection, and Supervision. 2nd ed. Newbury Park, CA: Sage Publications.

Lohr, Sharon L. 2010. Sampling: Design and Analysis, $2^{\text {nd }}$ ed. Boston: Brooks/Cole, Cengage Learning.

Malchow, Hal. 2008. Political Targeting, $2^{\text {nd }}$ ed. Predicted Lists LLC Publishing.

Malhotra, Neil and Jon A. Krosnick. 2007. "The Effect of Survey Mode and Sampling on Inferences about Political Attitudes and Behavior: Comparing the 2000 and 2004 ANES to Internet Surveys with Nonprobability Samples.” Political Analysis 15:286323.

Mann, Christopher B. 2005. “Do Advance Letters Improve Preelection Forecast Accuracy?” Public Opinion Quarterly 69:561-571.

Martin, Elizabeth, Michael Traugott, and Courtney Kennedy. 2005. "A Review and Proposal for a New Measure of Poll Accuracy.” Public Opinion Quarterly, 69: 342-369.

Perry, Paul. 1960. "Election Survey Procedures of the Gallup Poll.” Public Opinion Quarterly 24:531-42. 
Perry, Paul. 1979. "Certain Problems in Election Survey Methodology.” Public Opinion Quarterly 43:312-25.

Petrocik, John R. 1991. “An Algorithm for Estimating Turnout as a Guide to Predicting Elections.” Public Opinion Quarterly 55:643-47.

Pew Research Center for the People and the Press. 2012. "Assessing the Representativeness of Public Opinion Surveys.” Available at: http://www.people-press.org/files/legacypdf/Assessing\%20the\%20Representativeness \%20of\%20Public\%20Opinion\%20Surveys.pdf. [Accessed August 5, 2012].

Peytchev, Andy, Rodney K. Baxter, and Lisa R. Carley-Baxter. 2009. "Not All Survey Effort is Equal: Reduction of Non-response Bias and Non-response Error." Public Opinion Quarterly 73:785-806.

Rogers, Todd and Masa Aida. 2011. "Vote Self-Prediction Hardly Predicts Who Will Vote, And Is (Misleadingly) Unbiased." American Politics Research Published online before print September 5, 2013, doi: 10.1177/1532673X13496453.

Sanders, David, Harold D. Clarke, Marianne C. Stewart, and Paul Whiteley. 2007. "Does Mode Matter for Modeling Political Choice? Evidence from the 2005 British Election Study." Political Analysis 15:257-285.

Scheiber, Noam. 2012. “The Internal Polls That Made Mitt Romney Think He'd Win." The New Republic November 30, 2012.

["http://www.newrepublic.com/blog/plank/110597/exclusive-the-polls-made-mittromney-think-hed-win"]

Silver, Brian D., Barbara A. Anderson, and Paul R. Abramson. 1986. "Who Overreports Voting?” American Political Science Review 80:613-24.

Sokhey, Anand E. and Paul A. Djupe. 2013. "Name Generation in Interpersonal Political Network Data: Results from a Series of Experiments." Social Networks (in press).

Stephenson, Laura B., and Jean Crête. 2011. "Studying Political Behavior: A Comparison of Internet and Telephone Surveys." International Journal of Public Opinion Research 23:2455.

Traugott, Michael, 2012. "Methodological Trends and Controversies in the Media's Use of Opinion Polls" in Opinion Polls and the Media: Reflecting and Shaping Public Opinion, Christina Holtz-Bacha and Jesper Strömbäck, eds. Palgrave-Macmillan, New York.

Traugott, Michael W. and Clyde Tucker. 1984. "Strategies for Predicting Whether a Citizen Will Vote and Estimation of Electoral Outcomes.” Public Opinion Quarterly 48:330-43. 
Traugott, Michael. 2005. "The Accuracy of the National Pre-election Polls in the 2004 Presidential Election.” Public Opinion Quarterly, 69:642-654.

Traugott, Michael W. and Christopher Wlezien. 2009. "The Dynamics of Poll Performance During the 2008 Presidential Nomination Contest." Public Opinion Quarterly 73: 866894.

Visser, Penny S., Jon A. Krosnick, Jesse Marquette, and Michael Curtin. 1996. "Mail Surveys for Election Forcasting? An Evaluation of the Columbus Dispatch Poll" Public Opinion Quarterly 60:181-227.

Voss, D. Stephen, Andrew Gelman, and Gary King. 1995. "Pre-election Survey Methodology: Details from Eight Polling Organizations, 1988 and 1992.” Public Opinion Quarterly 59:98-132.

Weisberg, Herbert F. 2005. The Total Survey Error Approach: A Guide to the New Science of Survey Research. Chicago: University of Chicago Press.

Yeager, David S., Jon Krosnick, LinChiat Chang, Harold S. Javitz, Matthew S. Levendusky, Alberto Simpser, and Rui Wang. 2011. "Comparing the Accuracy of RDD Telephone Surveys and Internet Surveys Conducted with Probability and NonProbability Samples" Public Opinion Quarterly 75:709-747. 
Figure 1: Distributions of Predicted Probabilities of Voting

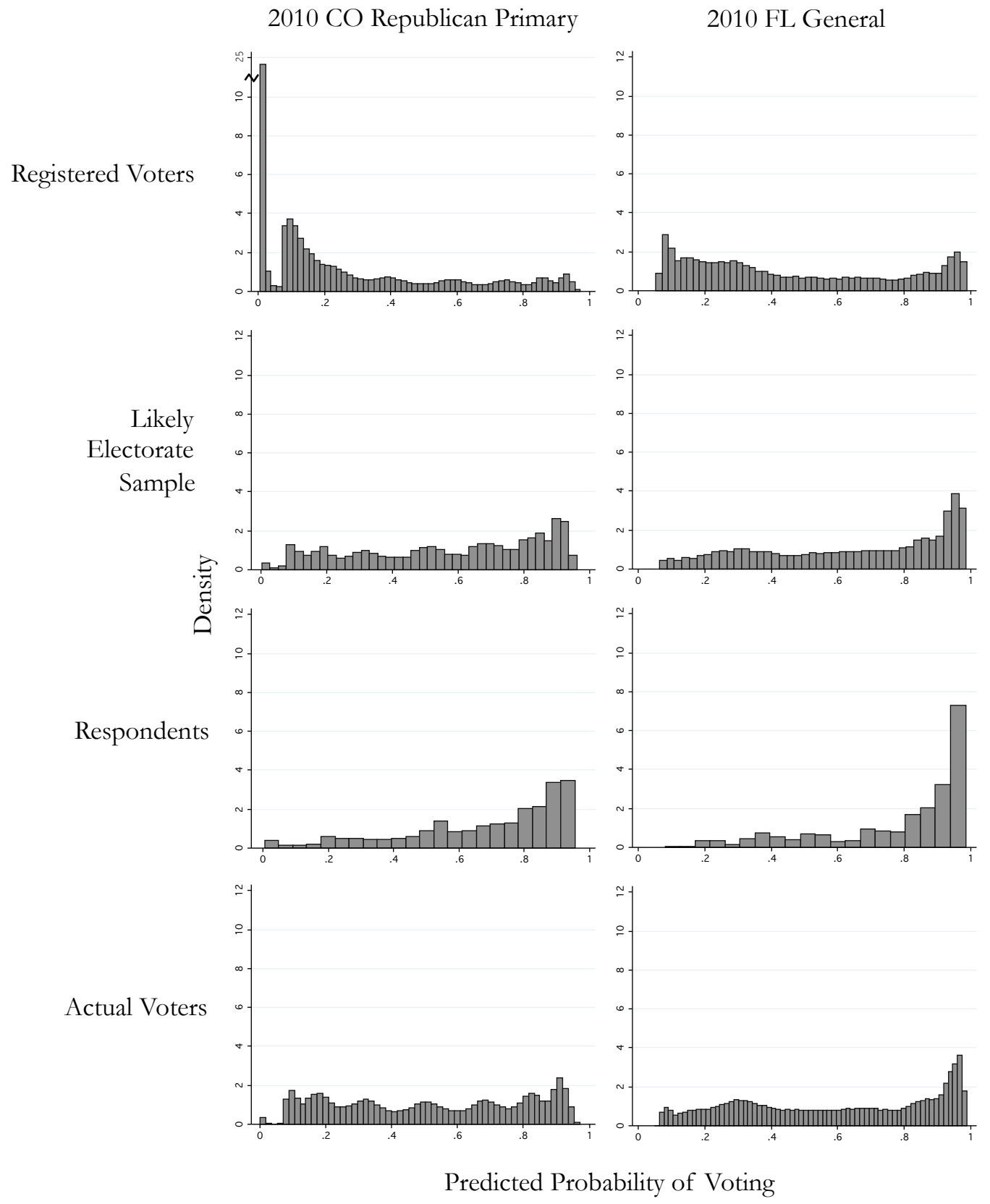

Each histogram shows the distribution across the predicted probabilities described in the paper. Each column is a different survey. Each row displays the distribution of probabilities for different stages of the process. The first row displays the distribution all registered voters (limited to those eligible to vote in the Republican primary in Colorado). The second row displays the distribution for sample of the predicted likely electorate. The third row displays the probability distribution for those that responded to each survey. The fourth row displays the distribution of predicted probabilities for all people that actually voted in the election based on public records of individual turnout. Histograms for all seven surveys are available in Figure S1 in the online Supplemental Materials. 
Figure 2: Poll Predictions Compared to Actual Election Results \& Public Polls

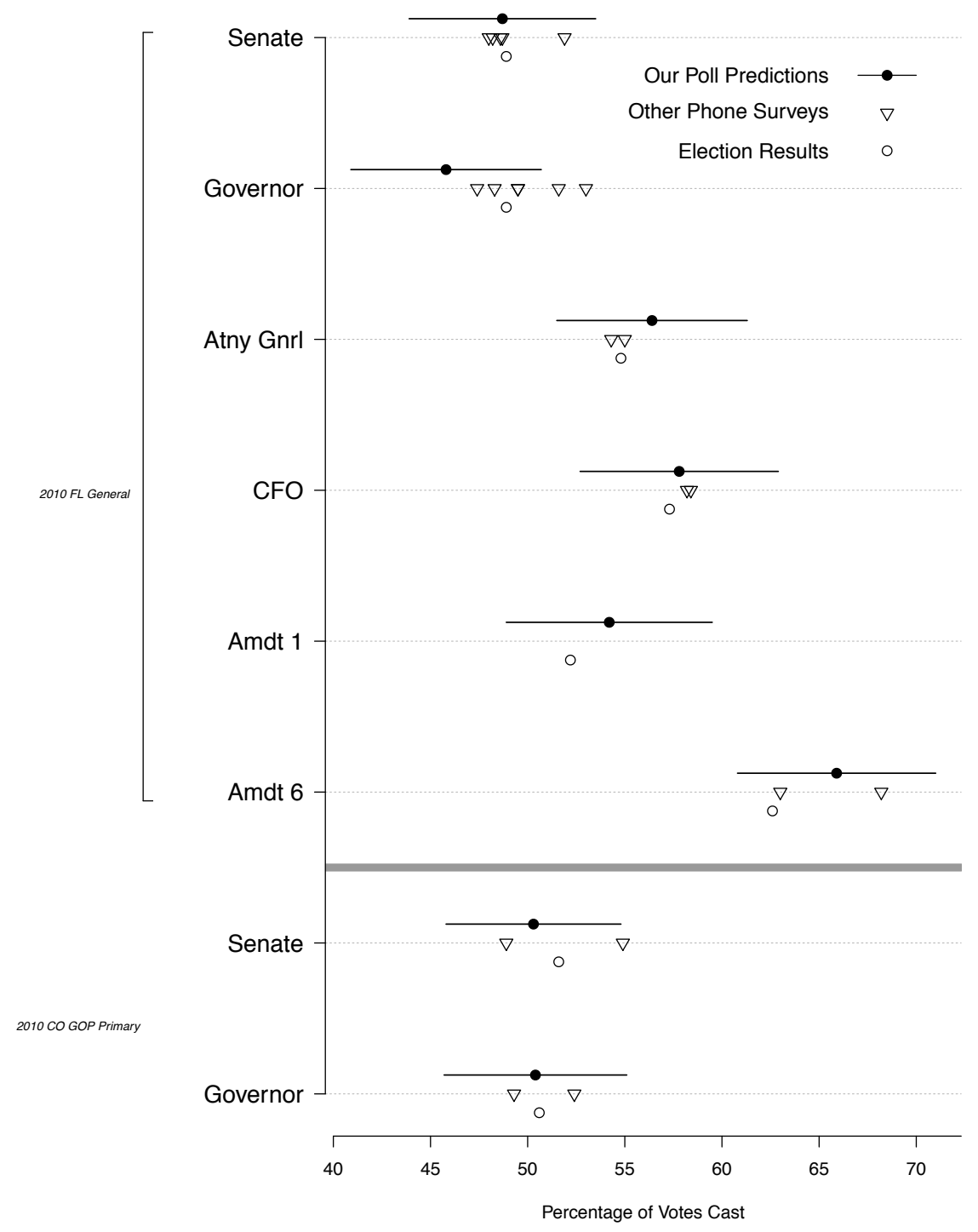

The vertical axis includes all contests in all seven surveys. For each race we display the poll prediction with corresponding 95\% margin of error for the winner of each race above the actual percentage of the race the winner obtained. Triangles indicate results of other telephone polls conducted during the same time our poll was in the field. These other polls often included an "undecided" option for each race. When plotting the predictions of the other polls, we allocate undecided responses to the candidates proportionately to gain a fair comparison to our polls, which did not include an undecided option. In all cases, the election outcome is contained within the margin of error. Figure S3 in the online Supplemental Materials reports the data for all seven surveys. Data for all surveys are available in Tables S2 and S3 in the online Supplemental Materials. 
Table 1: Descriptive Information for Each Survey

\begin{tabular}{|c|c|c|c|c|c|c|c|}
\hline Election Surveyed & Races Surveyed & Invitation Count & Response Number & Mailing Date & Election Date & Response Rate & Similar Past Election \\
\hline 2010 Florida General & $\begin{array}{l}\text { Governor } \\
\text { US Senate } \\
\text { Attorney General } \\
\text { Chief Financial Officer } \\
\text { State Constitutional Amendment } 1 \\
\text { State Constitutional Amendment } 6\end{array}$ & 9000 & 456 & October 25 & November 2 & $5.07 \%$ & 2006 General \\
\hline 2010 Colorado Statewide Republican Primary & $\begin{array}{l}\text { Governor } \\
\text { US Senate }\end{array}$ & 7200 & 541 & August 2 & August 10 & $7.50 \%$ & 2008 GOP Primary \\
\hline 2010 Colorado Statewide Democratic Primary & US Senate & 6800 & 588 & August 2 & August 10 & $8.66 \%$ & 2008 Dem Primary \\
\hline 2010 Utah 2nd District Democratic Primary & 2nd Congressional District & 8000 & 539 & June 11 & June 22 & $7.59 \%$ & 2008 Presidential Primary \\
\hline 2010 Utah Statewide Republican Primary & US Senate & 8000 & 475 & June 11 & June 22 & $8.35 \%$ & 2008 Presidential Primary \\
\hline 2008 Utah General & $\begin{array}{l}\text { President } \\
\text { Governor } \\
1-3 \text { Congressional Districts } \\
\text { Attorney General }\end{array}$ & 10000 & 627 & October 26 & November 8 & $6.96 \%$ & 2004 General \\
\hline 2008 Utah 3rd District Republican Primary & 3rd Congressional District & 10000 & 653 & June 12 & June 24 & $10.10 \%$ & 2006 3CD GOP Primary \\
\hline
\end{tabular}

